\title{
COVID-19: A PERSONALIZED CARDIOMETABOLIC APPROACH FOR REDUCING COMPLICATIONS AND COSTS. THE ROLE OF AGING BEYOND TOPICS
}

\author{
J. SABAN-RUIZ1 ${ }^{1}$ D. LY-PEN ${ }^{2}$ \\ 1. Head of Anti-Aging \& Cardiometabolic Health Unit, d-médical Clinic, Madrid, Spain. GenObia co-investigator (Madrid Community Project number S2017/BMD-3773).

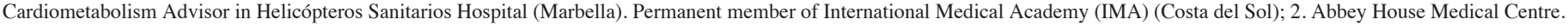 \\ Navan, Co Meath, Ireland. Corresponding author: Prof. Saban-Ruiz, MD, PhD, d-médical Clinic, Madrid, Spain, psaban@gmail.com
}

\begin{abstract}
COVID 19 is much more than an infectious disease by SARS-CoV-2 followed by a disproportionate immune response. An older age, diabetes and history of cardiovascular disease, especially hypertension, but also chronic heart failure and coronary artery disease among others, are between the most important risk factors. In addition, during the hospitalization both hyperglycaemia and heart failure are frequent. Less frequent are acute coronary syndrome, arrhythmias and stroke. Accordingly, not all prolonged stays or even deaths are due directly to SARS-CoV-2. To our knowledge, this is the first review, focusing both on cardiovascular and metabolic aspects of this dreadful disease, in an integrated and personalized way, following the guidelines of the Cardiometabolic Health/Medicine. Therefore, current personalized aspects such as ACEIs and ARBs, the place of statins and the most appropriate management of heart failure in diabetics are analysed. Aging, better than old age, as a dynamic process, is also considered in this review for the first time in the literature, and not only as a risk factor attributed to cardiovascular and non-cardiovascular comorbidities. Immunosenescence is also approached to build healthier elders, so they can resist present and future infectious diseases, and not only in epidemics or pandemics. In addition, to do this we must start knowing the molecular mechanisms that underlying Aging process in general, and immunosenescence in particular. Surprisingly, the endoplasmic reticulum stress and autophagy are implicated in both process. Finally, with a training in all the aspects covered in this review, not only the hospital stay, complications and costs of this frightening disease in high-risk population should be reduced. Likely, this paper will open a gate to the future for open-minded physicians.
\end{abstract}

Key words: Metabolic Syndrome, cardiometabolic syndrome, cardiometabolic risk, cardiometabolic health, atherothrombotic disease, endothelial dysfunction.

Introduction: historical perspective, original focus and pandemic expansion. Why a Cardiometabolic approach is necessary?

Coronavirus $(\mathrm{CoV})$ is a subfamily of virus with positive single-stranded RNA belonging to the coronaviridae family of the order of Nidovirales; they are responsible for diseases in animals ( $\mathrm{ACoV}$ ) but also in humans ( $\mathrm{HCoV})$. Other Nidovirales, like arteriviridae (1), are responsible for diseases only in animals, and the most important is the equine viral arteritis (2).

Until now, CoV had caused illnesses in human beings ranging from the common cold, the most frequent, to more severe diseases such as SARS (Severe Acute Respiratory Syndrome) and MERS (Middle East Respiratory Syndrome). In 2003, SARS-CoV involved 32 countries, with 8422 confirmed cases and $916(10.87 \%)$ casualties from November 2002 to August 2003 (3). In 2012, the MERS-CoV MERS-CoV spread over 27 states, causing 2496 cases and 868 casualties (34\%). The most affected patients produced an in Saudi Arabia with 124 cases and a mortality rate as high as $40 \%$. Isolated cases were subsequently diagnosed in other areas, the last one in 2015 (4).

A new coronavirus is responsible for the current pandemic with the initial focus in Wuhan (Hubei, China), in December 2019 (5). The latter expansion to South Korea, Spain and Italy took place at the end of January 2020. Therefore, on 30th January 2020, the World Health Organisation (WHO) declared the COVID-19 (Corona Virus Disease 2019) as an epidemic (6). On 11th February 2020, the WHO named this new disease as COVID-19 and the new virus as SARS-CoV2 (7). Finally, on 12th March 2020, the WHO announced the COVID-19 outbreak as a pandemic.

When we finished writing this paper, on 16th April 2020, 21:08 GMT, there were 210 countries from the 5 continents, 2,173,168 confirmed cases and 144,949 deaths. The average global Case Fatality Rate (CFR) is around 5\%, depending on the age, and is slightly higher in males than females (6).

In financial terms, this pandemic is triggering a major worldwide economic meltdown with the stock market flash crash. On 9th April 2020 the International Monetary Fund, a United Nations (UN) specialized agency, predicted that COVID-19 will trigger the worst economic fallout since the Great Depression of the early 1930s shortly after stock market crash of Black Tuesday on 29th October 1929.

Facing such health and economic events, why is a cardiometabolic approach necessary here and now? Recently, five reviews (8-12) about cardiovascular aspects of this terrible 
Table 1

Summary of five cardiovascular-related studies in COVID-19 patients

\begin{tabular}{|c|c|c|c|c|}
\hline Author & Journal / year & Diseases studied & Conclusions & Recommendations \\
\hline Driggin E et al & JACC 2020 & $\begin{array}{l}\text { Patient risk assessment: infection } \\
\text { and cardiovascular issues }\end{array}$ & $\begin{array}{l}\text { The COVID-19 has substantially } \\
\text { increased the difficulty of treating } \\
\text { patients with severe emergent CVD }\end{array}$ & $\begin{array}{l}\text { Individualized diagnosis and } \\
\text { treatment measures tailored to } \\
\text { specific local epidemic situations } \\
\text { should be developed }\end{array}$ \\
\hline Guo T et al & JAMA Cardiol 2020 & $\begin{array}{l}\text { Association of underlying CVD } \\
\text { and myocardial injury with fatal } \\
\text { outcomes in COVID-19 }\end{array}$ & $\begin{array}{l}\text { Myocardial injury is associated with } \\
\text { cardiac dysfunction, arrhythmias and } \\
\text { fatal outcome of COVID-19. The } \\
\text { prognosis of patients with underlying } \\
\text { CVD but without myocardial injury is } \\
\text { relatively favourable. }\end{array}$ & $\begin{array}{l}\text { Aggressive treatment may be } \\
\text { considered for patients at high } \\
\text { risk of myocardial injury }\end{array}$ \\
\hline Zheng YY et al & Nat Rev Cardiol 2020 & Underlying CVD & $\begin{array}{l}\text { COVID- } 19 \text { patients with underlying } \\
\text { CVD have an adverse prognosis }\end{array}$ & $\begin{array}{l}\text { Particular attention should be } \\
\text { given to } \mathrm{CV} \text { protection during } \\
\text { treatment for COVID-19 }\end{array}$ \\
\hline Madjid M et al & JAMA Cardiol 2020 & $\begin{array}{l}\text { Underlying CVD and/or cardiac } \\
\text { risk factors }\end{array}$ & $\begin{array}{l}\text { COVID-19 is associated with a high } \\
\text { inflammatory burden that can induce } \\
\text { vascular inflammation, myocarditis, and } \\
\text { cardiac arrhythmias. }\end{array}$ & $\begin{array}{l}\text { CV risk factors and conditions } \\
\text { should be controlled per } \\
\text { evidence-based guidelines }\end{array}$ \\
\hline Han Y et al & Circulation AHA 2020 & $\begin{array}{l}\text { Patient risk assessment of both } \\
\text { infection and } \mathrm{CV} \text { issues }\end{array}$ & $\begin{array}{l}\text { Patient risk assessment of both infection } \\
\text { and } \mathrm{CV} \text { issues. Consider the prevention } \\
\text { and control of COVID-19 transmission } \\
\text { as the highest priority }\end{array}$ & $\begin{array}{l}\text { Individualized diagnosis and } \\
\text { treatment measures tailored to } \\
\text { specific local epidemic situations } \\
\text { should be developed. }\end{array}$ \\
\hline
\end{tabular}

$\mathrm{CV}=$ cardiovascular, $\mathrm{CVD}=$ cardiovascular diseases

disease had been published, but none are about an integrated cardiometabolic approach (See Table 1). Our questions are, why?, and beyond, would it be useful?.

The term "Cardiometabolic Medicine" (CMM), synonym of "Cardiometabolic Health" (CMH), was launched officially in October 2006 in Boston, with the celebration of the first congress, a meeting point for physicians from different specialties, biologists, biochemists, pharmacists, cardiovascular bioengineers and researchers in all these fields. The term "cardiometabolic» had previously used by Pescatello in 1999 for obesity (13), by Sowers in 2001 for "CM Syndrome" (14), and by Vasudevan \& Ballantyne in 2005 (15) for "CM Risk» in two phases. Firstly, the term was used by Khan, Buse, Ferrannini and Stern in a symposium whose proceedings were never published. Fortunately, their conclusions were collected and valued as of great interest by other authors (Vasudevan \& Ballantyne); they published them that same year (15) laying the groundwork for a new enlightened medicine. This medicine, the CMM, is much more eagerly, dynamic, open that the classical cardiovascular medicine, and at the same time much more predictive, preventive and anticipatory. To topping it all off, the CMM is the prototype of the modern "Precision Medicine", on which the American government spent so many millions in research during the last decade (16).

This CMM approach is not new, we saw it was born starting this 21 st century, but we frequently forget, at the expense of the most classical cardiovascular term, actually dating from the 20th century. Despite the latter one, is still useful in certain specialties (Cardiology, Neurology and Vascular Surgery), it is seldom useful for defining prevention strategies. Therefore, CMM had allowed detection of causes and had predicted the consequences of a rise of cardiometabolic diseases across the world (especially in low- and middle-income countries) (17), and had proven to prevent and predict events (18), and at the same time, facilitating the cost analysis.

Bearing this in mind, it is quite likely, that if we have fewer complications, particularly severe ones (cardiac arrest, ventricular tachyarrhythmia, acute heart failure, acute coronary syndrome, haemorrhagic or massive ischaemic stroke), this integrated approach could cut down the elevated mortality in the highest risk group (cancer, COPD and oldest subjects with comorbidities), usually preceded by a multi-organ failure.

\section{The SARS-CoV-2 as new human Coronavirus}

Seven types of $\mathrm{HCoV}$ had been described. On one side, we have four genuinely human ones (229E, NL63, OC43 and KU1) which are responsible for almost $30 \%$ of common colds. On the other hand, three mutated variants of $\mathrm{ACoV}$ had been described (see below) causing zoonotic disease when infecting human beings (19). This happened also with the Nipah virus infection in 1998 (Malaysia) and 2004 (Bangladesh) from the so-called "fruit bat". After this outbreak, as they did after latest MERS epidemic, the CEPI (Coalition for Epidemic Preparedness Innovations), worked successfully on vaccines to prevent future epidemics with both viruses.

In relation to mutated $\mathrm{CoV}$ they are included strangely enough as $\mathrm{HCoV}$ (20). In either case, unlike the first group of 
$\mathrm{HCoV}$, they usually show a wide clinical range, with higher lethality in risk populations. Of course, we are speaking about SARS-CoV, MERS-CoV and SARS-CoV-2, responsible of SARS, MERS and COVID-19 respectively, three emerging $\mathrm{CoV}$ diseases in just two decades (21). MERS and SARS were probably originated from bats and then moving into other mammalian hosts (the Himalayan palm civet for SARS-CoV, and the dromedary camel for MERS-CoV) before jumping to humans. The exact role of bat and others mammalian hosts in this current pandemic is still under investigation.

Regarding $\mathrm{ACoV}$, the main target is usually the digestive tract, and rarely can induce a mild bronchitis $(22,23)$.

Like all coronaviruses, SARS-CoV-2 is composed of RNA involved by a glycoprotein and lipid membrane. This is not a specific membrane composition of this subfamily of viruses, but of all membranes of living beings, including plants (these are surrounded by a cell wall). This new virus' membrane contains moreover specific proteins of CoV named S, E, N and M proteins. Regarding the external is named "S" protein, forms spikes (hence its name), and have two subunits (S1 and S2) that allows it, if recognized by the right receptor (see below), to penetrate into the cells. From what is known so far in COVID19 , the mutation especially affects it, making it especially harmful. The "E" protein is key to infect other cells. The "N" protein, a haemagglutinin-esterase protein that allows them to camouflage the genetic material. Finally, the "M" (membrane) protein plays a central role in virus assembly, interacting through both the transmembrane domain and endodomain, turning cellular membranes into workshops where virus and host factors come together to make new virus particles (24).

Even more interesting, taking into account that at least 50\% of COVID-19 patients have hyperglycaemia on admission or in the first days of hospitalization (25), the transmembrane domain has a potential N-glycation site (26) that in COVID-19 would deserve further research. The reason is that other proteins (e.g. LDL, myelin-proteins, collagen, myosin) become more pathogenic when they bind non-enzymatically to glucose (27).

On the other hand, a host transmembrane serine protease, TMPRSS2, synthesized by the microvascular endothelium, promotes the entrance of SARS-Cov into the cells in two steps: firstly, TMPRSS2 acts on the S2 facilitating fusion of the virus to the cell membrane. Secondly TMPRSS2 activates the spike and cleaves the receptor that is ACE2 (Angiotensin-I Converting Enzyme-2), located in the pneumocytes type II, facilitating interaction and penetration (28). A recent report suggests a role for TMPRSS2 variants and expression levels in modulating COVID-19 severity (29).

\section{Clinical and pathogenic mechanism of respiratory airways and lung diseases. Immunologic implications}

Regardless the initial cases of the pandemic outbreak, that are still under investigation, all the cases after the second week, were inter-human transmission, with a mean incubation period of about 5.2 days. A single systematic review found no statistically significant difference in common symptoms between patients with severe or mild / moderate COVID-19 (30).

In an initial phase, the virus enters through the upper airway and may produce signs and symptoms like fever, malaise, myalgia and occasionally sore throat and sneezing. Afterwards, it descends into the lower airway and there it is responsible for a dry or barely productive cough. Not uncommonly, the virus colonizes the airway and patients remain asymptomatic for about two weeks; they can be contagious in this period, whilst this has not been documented in patients with common flu. Fever is the most common symptom, but is accompanied by generalized myalgia only in $44 \%$ of total affected, markedly different from the flu, where it is close to $100 \%$. Other frequent symptoms are cough (present in about $75 \%$ ), anosmia is a frequent symptom, up to $60 \%$ of confirmed cases in some series (30), headache and drowsiness $(<10 \%)$, and confusion $(<5 \%$, especially in older patients). Occasionally in this phase the patient may have sore throat, ageusia and rhinorrhoea $(<5$ $10 \%)$, and gastrointestinal reaction $(<10 \%)(7,25)$.

In a second phase, presumably preceded of a virus-receptor interaction (see below), it is possible a pulmonary involvement, but not always. If this happens, dyspnoea is more frequent in severe cases and, in some studies, is a marker of severe disease (30).

Dyspnoea usually coincides with the appearance of lung infiltrates in the chest X-ray and CT-scan.

In a third phase, by the seventh to the tenth day about $20 \%$ of patients can develop acute respiratory distress syndrome (ARDS) and $10 \%$ a multiple organ failure $(7,25)$.

Regarding lung involvement, the main target in COVID19, the SARS-CoV-2 induces a direct damage at this level, via the same receptor that SARS-CoV used in 2003 , the carboxypeptidase ACE2 (Angiotensin-I Converting Enzyme type 2) (31), the homologue of ACE, a dipeptidylcarboxypeptidase. ACE is the classical enzyme of RAS that cleaves angiotensin I to generate angiotensin II, which is a key effector peptide of the system and exerts multiple biological functions. ACE is occasionally named incorrectly as ACE1, is simply ACE because history, including the scientific history, cannot be rewritten. ACE is the main enzyme of the RAS with low ACE2 levels in blood (28) but these levels increase in patients treated with ACEIs/ARBs, generally with hypertension (HTN) and/or diabetes mellitus (DM) (32).

At a local level, RAS, with all its components such as ACE, renin, angiotensinogen and AII, was firstly reported in dog's brain and later in other organs $(28,33)$. ACE in vascular cells is expressed in the endothelial cells (EC) and smooth muscle cells (SMC) independently; so, ACE in SMC, unlike the EC, is insulin-dependent (34) including the lymphatic system. On their behalf, its homologue ACE2 is expressed mainly locally (by the local RAS) with a low production by the systemic RAAS axis which include, unlike the local system, the aldosterone in the 


\section{THE JOURNAL OF NUTRITION, HEALTH \& AGING}

equation. ACE2 is one of the type-I integral proteins, expressed fundamentally at the cell surface as an ectoenzyme and is found at heart, kidney, small intestine, lung (type II pneumocytes), pancreas and liver among others. The expression of ACE2 in the endothelium and vascular SMC opens an unexplored pathway in subjects with COVID-19 who develop acute coronary syndromes. It had been demonstrated that in patients treated with RAS-blockers, the risk of atherothrombosis decreases. This could be explained because by dampening local A-II and vice versa, an over activated ACE2 could produce the opposite effect (35); this does not happen in older people, because they have ACE2 expression reduced in all organs in which it has been described, but especially at the vascular level (36). At both the systemic and vascular level, ACE2 acts as a buffer, so that Angiotensin-II does not rise excessively when its receptor is exogenously blocked. Therefore, ACE2 is a key counter regulatory enzyme that degrades angiotensin II to angiotensin-(1-7), thereby attenuating its effects on vasoconstriction, sodium retention, and fibrosis. Although angiotensin II is the primary substrate of ACE2, that enzyme also cleaves angiotensin I to angiotensin-(1-9) and participates in the hydrolysis of other peptides (28). Both ACEs uses $\mathrm{Zn}^{2+}$ and $\mathrm{Cl}^{-}$as cofactors for being metalloproteases (37). It could have therapeutic implications especially in people who use zinc as a nutraceutical (38).

The ACE2, but not the ACE is expressed in the type II pneumocytes (28) but it cannot be ruled out that endothelial ACE2 could collaborate coming from neighbouring microvascular endothelial cells as demonstrated in SARS (39). The true physiological significance of ACE in the pneumocyte is currently unknown.

After learning the important role played by ACE2 in SARS and COVID-19, it is strange that the CoV NL63-S, which also binds to ACE2, do not cause severe lung disease (40). This would lead us to investigate a co-receptor in COVID-19, a pathway that is not being considered.

There is no doubt that in COVID-19, the immunology plays a relevant role from the beginning. In the initial contagiousness, the older people are more vulnerable because of their immunosenescence (41). Afterwards, the immunology is responsible of the fever, inducing the virus directly a secretion of MIP1a/ CCL3 by the macrophage in the phase 1 ; this is responsible of a monophasic fever at hypothalamic level (42), that is resistant to non-steroidal anti-inflammatory drugs (NSADs) (e.g. ibuprofen, a cyclooxygenase inhibitor). In contrast, the fever induced by Tumoral Necrosis Factor alpha $(\mathrm{TNF} \alpha)$ and Interleukin 1 (IL-1), the two usual endogenous pyrogens in flu and other viral infections, they do respond to NSAIDs (43).

Mainly in risk groups, by the seventh to the tenth day, some patients can develop a more severe phase; it has been correlated with chemokine secretion from endothelial cell (MCP-1) and the macrophage (CXCL10/IP-10). The massive knock-on (or pull effect) of chemokines attracts new macrophages, that are hyperactivated and release large amounts of cytokines, that can act locally or pass into the circulation. The more severe cases are related to a cytokine storm (commanded by IL6), related to a Macrophage Activation Syndrome (MAS), which is the cause not only of ADRS but occasionally, of myocarditis (see below), and in the most severe cases. Of a Multi-Organ Failure. This syndrome, initially described as Multiple Organ Dysfunction Syndrome (44), is not always lethal despite the impaired function of the liver, kidneys and brain (among other organs), but even when not lethal can leave disabilities in up to $15-20 \%$ of the patients.

\section{Insufficient response to the tested treatment. A change of strategy is urgent}

The genome of this mutated coronavirus, has been published recently (45) and it is the basis for the investigation of an adequate vaccine (46). Alignment of the full-length genome sequence showed that is a positive-sense RNA, 29903-bp (Watson-Crick base pairs) betacoronavirus. The closest relationship was with the bat SARS-like coronavirus strain (BatCov RaTG13), with 96\% identity. The other rational therapy, convalescent plasma transfusion (47), are not available at present.

In the meantime, different therapies have been tried and their results may be considered as frustrating in high risk groups (6). Recently, two antiviral agents, remdesivir and ivermectin, are being tested at a great scale. Remdesivir, a classical antiviral agent, up to now not traded worldwide (48); ivermectin, a classical antiparasitic drug recently approved by the FDA for this epidemic because of its antiviral action (49).

Regarding to hydroxychloroquine / azithromycin (HC/ AZ) and corticosteroids, two of the most tested therapies, we would like to point out a couple of comments related to their cardiometabolic aspects. Firstly, $\mathrm{HC}$ and $\mathrm{AZ}$ induce inhibition of cardiac hERG/IKr (rapid IK) potassium channel, inducing mild QT prolongation, with subsequent risk of ventricular arrhythmia and even cardiac arrest, thus needing QT monitoring. Secondly, high doses of corticosteroids not only produce hyperglycaemia in patients, even in not diabetics (50), but also raise blood pressure and in many cases lead to hypokalaemia, increasing the risk of arrhythmias. Other causes of non-diabetic hyperglycaemia, in many cases associated to corticosteroid administration would be high doses of loop diuretic, sepsis and very especially the enteral and parenteral nutrition $(50,51)$.

It is clear that we are still far from a useful vaccine and convalescent plasma transfusion. Furthermore, usual management of the disease is not enough, and two of the most commonly used treatments either have frequent side effects (corticosteroids) or have potentially severe adverse effects ( $\mathrm{HC} /$ AZ). The question now is, what can we do pro-actively, in the meantime? 


\section{What the truth does not hide: The COVID-19 is much more than an infectious disease and a dysfunctional immune response; it is also a cardiometabolic disease}

Within the cardiometabolic (CM) aspects of COVID-19, we first looked at DM and HTN. Both of them, in addition to be among the main risk factors for pandemic mortality, are strictly related to age, weight gain and low physical activity. DM and HTN form part of three syndromes closely related but not synonymous, the Metabolic Syndrome (MS) (52), the CM Syndrome (14) and the CM Risk (53). MS is the core of the other two (Figure 1), and CM risk is the core of CMM/CMH born just a year later.

In the past, during the SARS and MERS outbreaks, the high prevalence of DM and HTN was attributed to the age (54) but no further studies were conducted.

In COVID-19, in a population of 686 patients with mean age 48.9 years, $42.7 \%$ females, the composite endpoints that consisted of admission to the intensive care unit (ICU), invasive ventilation or death, were analysed. The most prevalent comorbidity was HTN followed by DM. After adjusting for age and smoking status, DM and HTN had similar hazard ratio of reaching to the composite endpoints, but they never overtook COPD nor cancer (55).

It is known that other RNA viruses such as enterovirus B, coxsackie (B1, B3 and B5) and human mastadenovirus $\mathrm{C}$ are implicated in autoimmune destruction of pancreatic islet $\beta$ cells, which results in a typical autoimmune T1DM (56). The question that immediately can be raised is if SARS-CoV-2 (also a RNA virus) is able to cause also a typical autoimmune T1DM. This possibility has not been discarded, but it would be more likely a not autoimmune, atypical T1DM (57). It looks strange that no cases of this type of DM had been described, in more than a million and a half test-confirmed patients, while in SARS, many cases were described in less than one thousand infected patients (58). The most surprising fact about this study, was that the pancreas damage was correlated with the expression of ACE2 in the endocrine tissues of the pancreas, leaving no doubt about a cause and effect relationship.

In relation to the heart, both HTN and DM can predispose to myocardiopathy (59) and in presence of viral respiratory infections, like flu annually (60) or now in COVID-19 (61), can predispose to heart failure (HF). This is without doubt the most frequent cardiac complication of these patients, especially if we add anaemia and/or tachyarrhythmia (flutter and atrial fibrillation, episodes of supraventricular or ventricular tachycardia) both not uncommon in Intensive Care Units (62, 63).

In addition, SARS-CoV-2 can induce severe myocarditis with TnT and NT-proBNP as biomarkers (64-66). This is not a surprise, because in animal models of $\mathrm{CoV}$, myocarditis was described almost 30 years ago, in 1992 (67); but in SARS, although creatine-kinase MB isoenzyme was a predictor for death (58) no study has demonstrated any case of well- documented myocarditis. COVID-19 patients who develop myocardial injury, usually DM and/or elderly patients, have a more acute presentation, with higher incidence of ADSR and more frequent need for assisted ventilation than those without myocardial injury (64).

The likely damage of the myocardium in COVID-19 may be, at least partially, from the release of cytokines and secondary activation of the NF-kB signalling pathway (68); actually, the virus cannot penetrate because this cell does not have a receptor for it (69). Although abundant ACE2 (SARS-CoV and SARS-CoV-2 receptor) immunostaining was found in the heart, unfortunately the authors did not specify if was in the endocardium and/or myocardium of the affected tissue (70).

In aged COVID-19 patients or with history of coronary artery disease (CAD) an acute coronary syndrome (ACS) can also be seen for plaque vulnerability in the presence of a pro-inflammatory state with cytokine release (71) but from the experience in animals, could it be plausible that any of them could be due to arteritis? As we already pointed out at the beginning of this paper, arteriviridae, of the order of Nidovirales (like the $\mathrm{CoV}$ ), are responsible of equine viral arteritis (EVA) (72) a disease that has too many similarities with COVID-19. The main one is that both of them can present with interstitial pneumonia and the microscopic findings, included diffuse alveolar damage with exudates, lymphocytic inflammation and multinucleated giant cells, suggesting hyperactive macrophages, were seen alongside large atypical pneumocytes (51). In EVA's necropsies, antigens can be demonstrated not only within the cytoplasm of the epithelial cells, but also within endothelial, macrophages and cardiac myocytes (51), something has not been proven in COVID-19, at least not yet.

It should also be considered in COVID-19 the suitable diagnosis and management of other vascular complications such as stroke and finger ischaemia, both frequent in the ICUs (73, $74)$.

\section{Practical aspects of COVID-19 regarding the personalized aspect of the Cardiometabolic Medicine}

If we look at Figure 1 and Table 2, we can observe that there are as many possible combinations as patients; that implies that treatments must be personalised. This had been advocated during last years by the most prestigious societies and institutes, such as the AHA, ADA, AACE, ESC, EASD and the NICE institute among others.

Among all these combinations, we have chosen the following three, because they are highly topical in the CMM. They can be applied to patients with COVID-19 in their acute phase of hospitalization or from the respiratory point of view, in a more stable phase (prehospitalization phase or when they are already convalescing at home).

The first aspect regarding personalised treatment is related to HTN and COVID-19, a debate about keeping or discontinuing 
Table 2

Cardiometabolic evaluation

(Excluding exhaustive metabolic and cardiovascular genetic evaluation)

\begin{tabular}{l}
\hline METABOLIC TESTS \\
\hline Glycaemia $^{I}$ and AIC (\%) Lipid profile: \\
- HDL-C and TG (Metabolic Syndrome) \\
- LDL-C ${ }^{2}$ (Cardiometabolic Risk) if FH is suspected request a genetic \\
LDL/ApoB100 receptor study \\
- ApoB and non-HDL-C (New targets alternative to LDL-C)
\end{tabular}

Glomerular Filtration Rate: Chronic Kidney Disease-Epidemiology Collaboration (CKD-EPI)

Ionic balance

$\mathrm{Na} / \mathrm{K}$

$\mathrm{Ca} / \mathrm{P}^{3}$

Albumin / Creatinine ratio (urine sample): Essential in DM and HTN or low/borderline GFR

\section{Emergent CV Risk Factors:}

High-sensitivity C-Reactive Protein

Homocysteine: if high request polymorphisms C 677T and A1298C of MTHFR gen

Lipoprotein (a): only in initial consultation

Uric acid: is always recommendable because it is related with MS, CMS and CMR, but especially if gout history or diuretic treatment

Ferritin $^{I}$ : especially recommendable if family history of hyperferritinaemia or fatty liver disease

If above the range request a genetic HFE test for study of polymorphisms HD63 and C282Y

Mutation G51C of IRE (iron responsive element) of L-ferritin gen

Hormonal \& Vitamins Study:

Hormones:

Women: $\beta$-estradiol / FSH / LH.

Men \& Women: TSH / testosterone / DHEA /

IGF-1

Cortisol in $24 \mathrm{~h}$-urine

Vitamins: Vitamin D: essential for right management of Aging /Folic acid and Vitamin B12

\section{Hypercoagulability study}

D-dimer; Prothrombin G20210A Factor II mutation; Factor V Leyden; Proteins $\mathrm{C}$ and S; Anti-phospholipid autoantibodies (aPL) : anticardiolipin (aCL) / anti antiphosphatidylserine; Anti-beta2-glycoprotein I antibodies (anti apo-H); Lupus anticoagulant LA: evidence of a circulating LA sensitive PTT or DRVVT diluted Russell Viper Venom test

NON-METABOLIC TESTS

Transthoracic Echocardiography: mandatory in suspected or diagnosed HTN, DM, .or in patients $\geq 60$, or stroke evaluation

Supra-aortic Trunks Ultrasound:

mandatory in DM, $\geq 60$ or history of CVD

Incipient Atherosclerosis Evaluation

Intima-media thickness (IMT)

Ankle-brachial index (ABI)

Ambulatory Blood Pressure Monitoring:

Mandatory in: non-controlled HTN, history of masked HTN, suspected "white coat" effect, suspected overtreatment.

24h-Holter Monitoring (ECG): if any of the following: sinus arrhythmia, bradycardia, tachycardia, anaemia, hyperthyroidism, extrasystole, complete LBBB, short PR, prolonged corrected QT

Arterial stiffness evaluation: In HTN and in the course of an Aging evaluation Pulse wave amplitude (PWA)

Pulse wave velocity (PWV)

Coronary Calcium Score (CAC): with CCT

If $\geq 60$ with no risk factors; $\geq 50$ with 1 risk factor; $\geq 45$ if T1DM, FH or cardiovascular family history of premature coronary disease

Cardiorespiratory fitness (CRF): VO2-Max

Direct (cycle ergometry)

Indirect (Balke Treadmill Test)

Endothelial F unction Study

-microvascular: EndoPAT / DRT4-lasser

-macrovascular: Celermajer test

Especific imaging techniques

Craneal CT / RM: for cerebral small vessel disease

study, including «white matter lesions» and «lacunar infarcts»

Cardio-RM: old necrosis / current ischemia / EF

Angio-CT: evaluation of a stenosis detected by doppler / possibility of stent

Angio-MR: alternative to the $\mathrm{CT}$ in stenosis evaluation

Noninvasive testing in myocardial ischemic evaluation (CAC Score $>75$ th percentile) Stress echocardiography, on treadmill or bike or drugs (dobutamine)

Ergometry with submaximal Bruce protocol

99m Tc-MIBI-SPECT if necessary: LBBB, females

Optional Tests:

Handgrip: essential in an Aging evaluation

Interventionist catheterism if required

CT: Computed tomography; CCT: Cardiac computed tomography. CVD: Cerebrovascular diseases; DHEA: Dehydroepiandrosterone. DM: Diabetes mellitus. EF: Ejection fraction; FH: Familial hypercholesterolemia activity. FSH: Follicle stimulating hormone. GFR: Glomerular Filtration Rate. HFE (gene and protein implicated in HH: Hereditary Hemochromatosis): High FE2+. HTN: hypertension. IGF-1: Insulin-like growth factor-1. LH: Luteinising hormone. LBBB: Left bundle branch block. TG: Triglycerides. TSH: Thyroid-stimulating hormone; (1) In hospital setting, glycaemia, hsCRP and ferritin are not valuable in a basal cardiometabolic status. Must be repeated at 2-month follow-up; (2) LDL-P (particle) (nmol/L) better than LDL-C if a Nuclear Magnetic Resonance Spectroscopy is available; (3) If Ca is high or P is low: Request PTH (parathyroid hormone). Also request PTH, if GFR is $<50$; (4) As stress measure in Aging and as diagnostic tool in patients with suspected secondary HTN.

ACEIs and ARBs started. The European Medicines Agency (EMA), European Society Cardiology (ESC) and American College Cardiology (AMC) all agreed that they should be continued in well-controlled patients and also in patients with previous cardiovascular pathologies of various kinds $(28,32)$.

Whilst discussing the above, a new debate has emerged with force: whether to start ACEIs/ARBs in patients without another clinical indication or not. Based upon what we had learned from SARS, the biological plausibility of salutary effects of ACEIs/ARBs in those with COVID-19 is intriguing (28) (32). Moreover, according to the group of experts of the National Institute of Aging (NIA) in Baltimore, (36) older individuals 
have reduced ACE2 expression and upregulation of angiotensin II (AII) and consequently its proinflammatory signalling way could be hyper-activated. The increase in ACE2 levels, and consequent reduction of AII, ACEIs/ARBs treatment would be especially beneficial for this age subgroup, in line with the evidence of a protective role of AII antagonism against sepsisassociated acute lung injury (22).

Figure 1

Cardiometabolic syndrome and Cardiometabolic risk

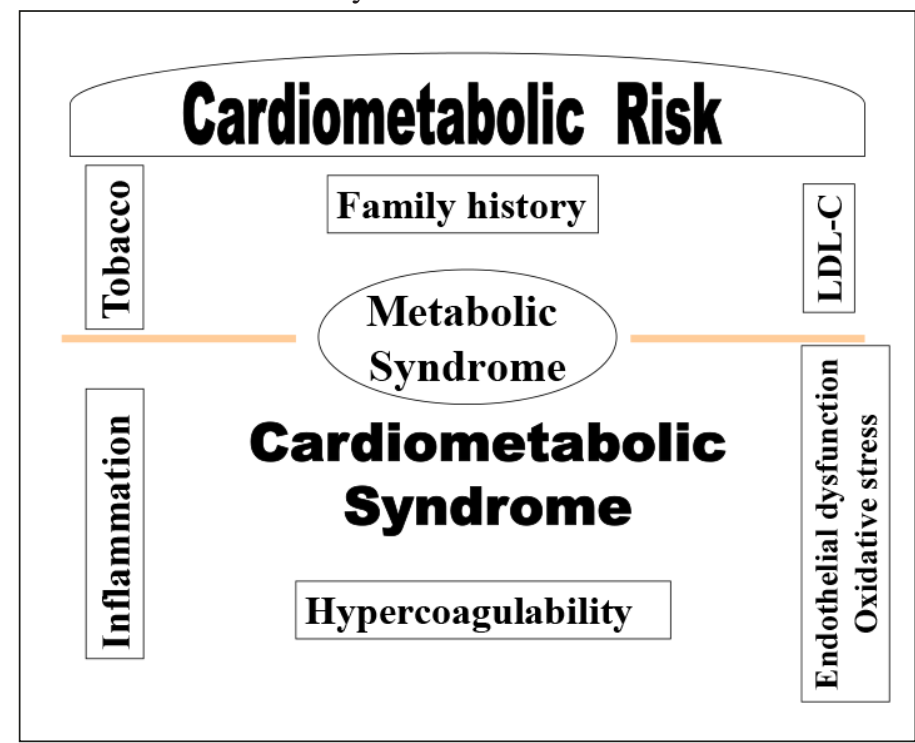

Cardiometabolic Syndrome (Sowers et al 2001): Gathering the classic components of the Metabolic Syndrome (Central obesity, hyperglycaemia, low HDL, hypertriglyceridaemia, pre-hypertension or hypertension) and adding endothelial dysfunction, oxidative stress, and inflammation and hypercoagulability biomarkers. Cardiometabolic Risk (Khan, Buse, Ferrannini and Stern, 2005): The Cardiovascular Risk maintains the Metabolic Syndrome as its core, and includes what the Cardiometabolic Syndrome had provided. It only keeps the inflammatory and hypercoagulability biomarkers, leaving the rest of biomarkers (Endothelial Dysfunction and Oxidative Stress) for research. Apart from the above, their main contribution was to add classic risk factors, not related to insulin resistance such as a family history of premature coronary disease $(<55$ in male / $<65$ in female), LDL-C and tobacco use.

On the other hand, SARS-Cov-2 particularly attacks DM patients (75), more frequently and with greater severity, being DM the cardiometabolic disease par excellence because they are often accompanied by other risk factors and atherotrombotic disease (ATD) (76). From lessons learned from experimental DM, we know that affected animals have a decreased vascular expression of ACE2, and it has been associated with an increased predisposition to ATD, coincidentally, as in elderly patients (77). This would lead us to extend the trials with RASblockers recommended by the NIA (36), if it were not for the fact that most of them are already on that treatment.

The second aspect should be regarding the use of statins, the star drug treatment of $\mathrm{CMM} / \mathrm{CMH}$ in an outpatient context. This is a subject of debate in hospitalized patients except for those with previous history or recent stroke or ACS, and possibly in those with familiar hypercholesterolemia, but only if a prolonged benefit is presumed. Apart from this, the risk/ benefit balance in patients with COVID-19 remains to be clarified.

The third aspect would be the combination of T2DM and Heart failure (HF) (the most frequent cardiac complication in any of the phases of the disease), which is present in a high percentage of patients, especially those at higher risk. Excluding secondary DM (corticosteroids, diuretics, sepsis, enteral / parenteral nutrition), these patients would benefit from taking a SGLT2 inhibitors (Sodium-glucose co-transporter-2, or gliflozins) (78) when they are in a stable phase. In these patients, the risk of ketoacidosis is quite low, but it may happen in the hospitalized patient (myocardial or cerebral infarction, sepsis ...) and more likely, if they are being treated with these drugs.

A recent theory explains that at least one of the mechanisms about the Metabolic Syndrome genesis could be a chronic activation of the sympathetic nervous system. According to this theory, SGLT2 inhibitors could have strong beneficial effects, not only in heart failure but also in a general CV level. This likely CV protection by SGLT2 inhibitors is detailed in Figure $2(78)$.

\section{Figure 2}

Proposed mechanism of cardiovascular protection by SGLT2 inhibitors

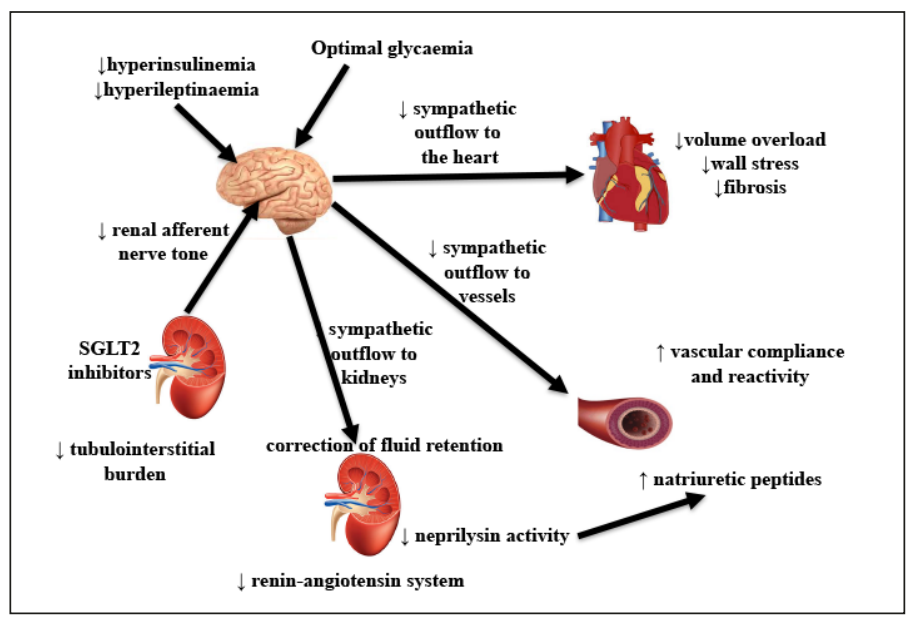

According to this theory, a chronic activation of the sympathetic nervous system plays a key role in the Metabolic Syndrome. Adapted from Sano M, 2018 J Cardiol 71:471-476 (Reference 78)

Furthermore, in HF we should consider not only the association with DM, but also its type; i.e., if HF is acute or chronic, and if chronic, to consider if reduced or preserved ejection fraction (HFrEF or HFpEF), because they have different therapeutic approaches (79).

Synthesising all the above, it looks like we are facing a disease, which is much more than an infectious/immune respiratory disease: simultaneously, it is also a cardiometabolic disease. The respiratory side is well known and managed, with poor results in the risk group, exactly the one that has more cardiometabolic alterations. Regarding this group of disorders, 


\section{THE JOURNAL OF NUTRITION, HEALTH \& AGING}

discussed in detail above, we do not know why they are always approached separately, when there are many advantages of their overall management, and it would have an unavoidable impact on morbidity, lethality and costs as demonstrated in patients followed up in outpatient clinic $(27,28)$.

In this sense, are we really optimizing the main targets during the hospitalisation? Do we give the value it really has? We are not speaking of LDL-cholesterol, as in the case of high $\mathrm{CV}$ risk patients followed as outpatients. In the presence of recent events where the LDL can be important, but even more important is the inflammation, to justify treatment with statins (80). Except in this last group, we speak of high and low blood pressure and/or high and low glycaemia, both type of decompensations are important in the two diseases. However, if we have to choose in the case of blood glucose, hypoglycaemia can have more serious consequences, especially in older patients, as the ADA stated in their last report (81).

Furthermore, we talk also of early detection and treatment of heart failure, arrhythmia or stroke that can go unnoticed in ICU patients with induced coma, and so many more aspects that should not be overlooked by monitoring only the lung disease when this is not the one that will always kill our patients.

\section{Common molecular aspects between cardiometabolic diseases and Aging. Do they embrace the immunosenescence also?}

One of the great advantages that CMM has over classic CV medicine, and that we did not say previously, is that CMM is seriously concerned with aging, both at clinical level (for healthy aging) and at research level.

In the same sense, whilst most researchers and clinicians interested in COVID-19 have attributed its greater aggressiveness to previous comorbidities (6), as convinced CMM supporters and of its interest in the aging process, we believe that despite our suspicions are correct, this is not enough. We will review the molecular aspects that underlie human aging and whether any of these mechanisms are involved in immunosenescence. If this is true, it will be easier in the future to deal with the whole process of aging, by slowing down the harmful processes and favouring the beneficial ones.

A modern theory of aging named «A Vascular Theory of Aging» (81), has rescued from oblivion two old aphorisms: «man has the age of his arteries» (Thomas Sydenham, 17th century) and «man has the age of his endothelium» (Rudolf Altschul) (82). Both were visionaries, but especially the latter when he published his book (in 1954) without even knowing the nitric oxide, the main endothelial product, discovered in the 1980s, leading Furchgott, Ignarro and Murad, to be recognized as the Nobel Prize in Physiology or Medicine in 1998.

Advances in the physiology in the last decade consider atherothrombosis and aging as an inflammatory disorder (81) but, which molecular aspects are common to both conditions? There are many important molecular aspects involving them, but the principal one is the combined activation of what we consider as the «lethal triad». The three elements of this triad are: 1) the mTOR (mammalian target of rapamycin), 2) the NF-kB (Nuclear Factor Kappa-B) signalling pathways (83) on one side, and 3) the NOX enzymes (84) of the submembranous cytoplasm on the other side, which release more free radicals than the mitochondria itself.

This triad alters the lipidoma at three levels, (membranous, cytoplasmic and circulating), as well as the so-called endoplasmic reticulum stress. This is a key process to understand both the endothelial dysfunction (85) preceding atherotrombotic disease (ATD), and the dysfunction of the beta cell (86) in T2DM and in the aging process (87) in part by the endothelial dysfunction at microvascular level within of vascular theory of aging (81). Fortunately, autophagy and especially mitophagy (mitochondrial autophagy) (88) protect us from apoptosis (programmed cell death), as long as our genetics and epigenetics (influenced by healthy nutrition and regular physical activity) allow it.

Finally, regarding the immunosenescence, its three hallmarks are: 1) the reduction in the number of peripheral blood naïve $\mathrm{T}$ cells population; 2) a relative increase in the frequency of CD28 memory T-cells subset, and 3) a lowgrade chronic inflammation that characterizes aging: "inflammaging" or "inflammaging" (89). Surprisingly, there are extensive data showing, moreover, that latent persistent human cytomegalovirus infection is also associated with age-related immune dysfunction in the $\mathrm{T}$ cells, which might enhance immunosenescence. In this way, in the case of COVID-19, in older groups, a virus could be predisposing to another virus (90). If we can still get even more surprised, both the endoplasmic reticulum stress and autophagy are involved in the process of immunosenescence (91). In accordance with the above, could the immunosenescence be related to the special aggressiveness of COVID-19 in the elderly?

\section{Conclusions}

The coronavirus disease 2019 (COVID-19) outbreak is evolving rapidly worldwide. From a dangerous situation due to its respiratory facet, there is another less well-known one (at least up to now), the cardiometabolic facet that can precede, accompany or even kill us if we do not keep our eyes open.

The high lethality of SARS-COV-2 in subjects with previous hypertension, diabetes and atherotrombotic disease. In addition to several cardiovascular complications arising during the hospitalization, include severe arrhythmias, acute heart failure by myocarditis and stroke. Often forgotten in reported series, are an ample justification that we are dealing with a disease of a great cardiometabolic potential that we should not overlook.

Other cardiometabolic aspects, like the possible N-glycation of viral protein $\mathrm{M}$ in patients with hyperglycaemia will need further investigation. In addition, the role of serinprotease TMPRSS2, synthesized by the endothelium and involved 


\section{COVID-19: A PERSONALIZED CARDIOMETABOLIC APPROACH FOR REDUCING COMPLICATIONS AND COSTS}

in the interaction of the virus with its recipient, could be a potential target for the treatment. Its secretion is not the unique endothelial product, also ACE2, considered only of pulmonary origin could derive from the microvascular endothelium as demonstrated in SARS.

The role of convalescent plasma transfusion and recent antiviral agents such as ivermectin and remdesivir, in improving COVID-19 prognosis in high-risk patients remains to be demonstrated.

In the meantime, here we have learned that Cardiometabolic Medicine could help us to reduce, using an anticipative and integrated approach, the morbidity and mortality related to this current SARS-CoV-2 pandemic while reducing costs.

Finally, the molecular aspects of aging in general and in the immunosenescence in particular, will serve us better in the near future. Knowing what happens, the solution is a matter of time. With healthier old people, we will make it more difficult for viral infections in general, not only in the course of epidemics or pandemics. On the other hand, in these situations, the best way for prevention is to not let them happen and for this purpose, CEPI (Coalition for epidemic preparedness innovations) exists, let us help them with more resources.

Acknowledgment: The authors are indebted to Dr. Joseph Hogg, partner at Abbey House Medical Centre, for his critical review, helpful comments and careful English revision.

Conflict of interest: None declared.

Ethical Standards: Not applicable.

\section{References}

1. Lavi E, Schwartz T, Jin YP, Fu L. Nidovirus infections: experimental model systems of human neurologic diseases. J Neuropathol Exp Neurol 1999;58:1197-1206

2. Cruz F, Newton R, Sanchez A, Ireland J, Mughini-Gras L, Moreno MA, Fores P Equine viral arteritis in breeding and sport horses in central Spain. Res Vet Sci 2017;115:88-91. DOI: 10.1016/j.rvsc.2017.01.022

3. Bell DM. World Health Organization Working Group on International and Community Transmission of SARS. Public health interventions and SARS spread, 2003. Emerg Infect Dis 2004;10:1900-1906.

4. Wernery U, Lau SK, Woo PC. Genomics and zoonotic infections: Middle East respiratory syndrome. Rev Sci Tech 2016;35:191-202.

5. Li Q, Guan X, Wu P, Wang X, Zhou L, Tong Y et al. Early Transmission Dynamics in Wuhan, China, of Novel Coronavirus-Infected Pneumonia. N Engl J Med 2020;382:1199-1207

6. Guo YR, Cao QD, Hong ZS, Tan YY, Chen SD, Jin HJ et al. The origin, transmission and clinical therapies on coronavirus disease 2019 (COVID-19) outbreak - an update on the status. Mil Med Res 2020;7:11. doi: 10.1186/s40779-020-00240-0.

7. Meo SA, Alhowikan AM, Al-Khlaiwi T, Meo IM, Halepoto DM, Iqbal M et al. Novel coronavirus 2019-nCoV: prevalence, biological and clinical characteristics comparison with SARS-CoV and MERS-CoV. Eur Rev Med Pharmacol Sci. 2020;4:2012-2019.

8. Driggin E, Madhavan MV, Bikdeli B, Chuich T, Laracy J, Bondi-Zoccai G et al. Cardiovascular Considerations for Patients, Health Care Workers, and Health Systems During the Coronavirus Disease 2019 (COVID-19) Pandemic, Journal of the American College of Cardiology, 2020;doi: https://doi.org/10.1016/j.jacc.2020.03.031.

9. Guo T, Fan Y, Chen M, Wu X, Zhang L, He T et al. Cardiovascular Implications of Fatal Outcomes of Patients With Coronavirus Disease 2019 (COVID-19). JAMA Cardiol, 2020. doi:10.1001/jamacardio.2020.1017 Published online March 27, 2020

10. Zheng YY, Ma YT, Zhang JY, Xie X. COVID-19 and the cardiovascular System. Nat Rev Cardiol. 2020;Mar 5. doi: 10.1038/s41569-020-0360-5

11. Madjid M, Safavi-Naeini P, Solomon SD, Vardeny O. Potential Effects of Coronaviruses on the Cardiovascular System. A Review. JAMA Cardiol. Published online March 27, 2020. doi:10.1001/jamacardio.2020.1286

12. Han Y, Zeng H, Jiang H, Yang Y, Yuan Z, Cheng X et al. CSC Expert Consensus on Principles of Clinical Management of Patients with Severe Emergent Cardiovascular Diseases during the COVID-19 Epidemic, 2020. 10.1161/ CIRCULATIONAHA.120.047011

13. Pescatello LS. Exercise prescription and management for cardiometabolic health ACSM Health Fitness J 1999;3:15-21

14. Sowers JR. Update on the cardiometabolic syndrome. Clin Cornerstone 2001;4:17-23. DOI: 10.1016/s1098-3597(01)90026-2

15. Vasudevan AR, Ballantyne CM. Cardiometabolic risk assessment: an approach to the prevention of cardiovascular disease and diabetes mellitus Clin Cornerstone 2005;7:7 16.

16. Hodson R. Precision medicine. Nature 2016;537, S49 https://doi.org/10.1038/537S49a

17. Miranda JJ, Barrientos-Gutiérrez T, Corvalan C, Hyder AA, Lazo-Porras M, Oni T et al. Understanding the rise of cardiometabolic diseases in low- and middle-income countries. Nat Med 2019;25, 1667-1679

18. Rao G. Prevention or reversal of cardiometabolic diseases. J Clin Prev Cardiol 2018;7:22-28

19. Plowright RK, Parrish CR, McCallum H, Hudson PJ, Ko AI, Graham AL, LloydSmith JO. Pathways to zoonotic spillover. Nat Rev Microbiol 2017;15:502-510

20. Pyrc K, Berkhout B, van der Hoek L. Identification of new human coronaviruses. Expert Rev Anti Infect Ther 2007;5:245-253

21. Guarner J. Three Emerging Coronaviruses in Two Decades The Story of SARS, MERS, and Now COVID-19. Am J Clin Pathol 2020;153:420-421.

22. Imai Y, Kuba K, Penninger JM. The discovery of angiotensin-converting enzyme 2 and its role in acute lung injury in mice. Exp Physiol 2008;93: 543-548.

23. Chan JF, To KK, Tse H, Jin DY, Yuen KY. Interspecies transmission and emergence of novel viruses: lessons from bats and birds. Trends Microbiol 2013;21:544-555

24. Neuman BV, Kiss G, Kunding AH , Bhella D, Baksh MF, Connelly S et al. A structural analysis of $\mathrm{M}$ protein in coronavirus assembly and morphology. J Struct Biol 2011;174: 11-22. doi: 10.1016/j.jsb.2010.11.021

25. Huang C, Wang Y, Li X, Ren L, Zhao J, Hu Y et al. Clinical features of patients infected with 2019 novel coronavirus in Wuhan, China. Lancet 2020;15;395:497-506) doi: 10.1016/S0140-6736(20)30183-5

26. Mounir S, Talbot PJ. Sequence analysis of the membrane protein gene of human coronavirus OC43 and evidence for O-glycosylation. J Gen Virol 1992;73:2731-2736.

27. Welsh KJ, Kirkman MS, Sacks DB. Role of Glycated Proteins in the Diagnosis and Management of Diabetes: Research Gaps and Future Directions. Diabetes Care. 2016;39:1299-1306

28. Vaduganathan M, Vardeny O, Michel T, McMurray JJV, Pfeffer MA, Solomon SD. Renin-Angiotensin-Aldosterone System Inhibitors in Patients with Covid-19. N Engl J of Med March 2020;30, Doi: 10.1056/NEJMsr2005760

29. Asselta R, Paraboschi EM, Mantovani A, Duga S. ACE2 and TMPRSS2 variants and expression as candidates to sex and country differences in COVID-19 severity in Italy. MedRxiv, 2020;DOI: 10.1101/2020.03.30.20047878

30. Michelen M, Jones N, Stavropoulou C, on behalf of the Oxford COVID-19 Evidence Service Team Centre for Evidence-Based Medicine, Nuffield Department of Primary Care Health Sciences, University of Oxford (2020) In patients of COVID-19, what are the symptoms and clinical features of mild and moderate cases? April 1, 2020. https:// www.cebm.net/covid-19/in-patients-of-covid-19-what-are-the-symptoms-and-clinicalfeatures-of-mild-and-moderate-case/

31. Hamming I, Timens W, Bulthuis ML, Lely AT, Navis G, van Goor H. Tissue distribution of ACE2 protein, the functional receptor for SARS coronavirus. A first step in understanding SARS pathogenesis. J Pathol 2004;203:631-637

32. Bavishi Ch, Maddox ThM, Messerli FH. Coronavirus Disease 2019 (COVID-19) Infection and Renin Angiotensin System Blockers JAMA Cardiol. Published online April 3, 2020. doi:10.1001/jamacardio.2020.1282

33. Paul M, Poyan Mehr A, Kreutz R. Physiology of local renin-angiotensin systems Physiol Rev 2006;86:747-803

34. Kamide K, Rakugi H, Nagai M, Takiuchi S, Matsukawa N, Higaki J et al. Insulinmediated regulation of the endothelial renin-angiotensin system and vascular cell growth. J Hypertens 2004;22:121-127

35. Zhang C, Zhao YX, Zhang YH, Zhu L, Deng BP, Zhou ZL et al. Angiotensinconverting enzyme 2 attenuates atherosclerotic lesions by targeting vascular cells. Proc Natl Acad Sci USA 2010;107:15886-15891

36. AlGhatrif M, Cingolani O, Lakatta EG. The Dilemma of Coronavirus Disease 2019, Aging, and Cardiovascular Disease. Insights From Cardiovascular Aging Science. JAMA Cardiol. Published online April 3, 2020. doi:10.1001/jamacardio.2020.1329

37. Guy JL, Jackson RM, Acharya KR, Sturrock ED, Hooper NM, Turner AJ. Angiotensin-converting enzyme-2 (ACE2): comparative modeling of the active site, specificity requirements, and chloride dependence. Biochemistry 2003;42:13185-92

38. Roohani N, Hurrell R, Kelishadi R, Schulin R. Zinc and its importance for human health: An integrative review. J Res Med Sci 2013;18:144-157

39. Li J, Gao J, Xu YP, Zhou TL, Jin YY, Lou JN. Expression of severe acute respiratory 


\section{THE JOURNAL OF NUTRITION, HEALTH \& AGING}

syndrome coronavirus receptors, ACE2 and CD209L in different organ derived microvascular endothelial cells. Zhonghua Yi Xue Za Zhi 2007;27;87:833-837

40. Hofmann H, Pyrc K, van der Hoek L, Geier M, Berkhout B, Pöhlmann S. Human coronavirus NL63 employs the severe acute respiratory syndrome coronavirus receptor for cellular entry. Proc Natl Acad Sci USA 2005;102:7988-7993

41. Tchkonia T, Zhu Y, Deursen JV, Campisi J, Kirkland JL. Cellular senescence and the senescent secretory phenotype: therapeutic opportunities. J Clin Invest 2013;123: 966-972

42. Miñano FJ, Sancibrian M, Myers RD. Fever induced by macrophage inflammatory protein-1 (MIP-1) in rats: hypothalamic sites of action. Brain Res Bull 1991;27:701-6

43. Dinarello CA. The history of fever, leukocytic pyrogen and interleukin-1. Temperature (Austin) 2015;2: 8-16). doi: 10.1080/23328940.2015.101708

44. Baue AE. Multiple, Progressive, or Sequential Systems Failure. A Syndrome of the 1970s Arch Surg 1975;110:779-781

45. Lu R, Zhao X, Li J, Niu P, Yang B, Wu H, et al. Genomic characterisation and epidemiology of 2019 novel coronavirus: implications for virus origins and receptor binding. Lancet 2020;22;395:565-574

46. Lurie N, Saville M, Hatchett R, Halton J. Developing Covid-19 Vaccines at Pandemic Speed. N Engl J Med March 30, 2020;Doi: 10.1056/NEJMp2005630

47. Roback JD, Guarner J. Convalescent plasma to treat COVID-19: Possibilities and challenges. JAMA Mar 27. 2020;doi: 10.1001/jama. 2020. 4940)

48. Wang M, Cao R, Zhang L, Yang X, Liu J, Xu M, Shi Z, Hu Z, Zhong W, Xiao G. Remdesivir and chloroquine effectively inhibit the recently emerged novel coronavirus (2019-nCoV) in vitro. Cell Res 2020;Feb 4; [e-pub]. https://doi.org/10.1038/s41422020-0282-0

49. Caly L, Druce JD, Catton MG, Jans DA, Wagstaff KM. The FDA-approved Drug Ivermectin inhibits the replication of SARS-CoV-2 in vitro. Antiviral Resarch 104787 2020. doi:10.1016/j.antiviral.2020.104787

50. Corsino L, Dhatariya K, Umpierrez G. Management of Diabetes and Hyperglycemia in Hospitalized Patients. www.endotext.org. October 1, 2017.

51. Gosmanov AR, Umpierrez GE. Management of Hyperglycemia during Enteral and Parenteral Nutrition Therapy. Curr Diab Rep 2013;13: 155-162

52. Hanefeld M, Leonhardt W. Das metabolische Syndrom. Dt Gesundheitswesen 1981;36:545-551

53. Vasudevan AR, Ballantyne CM. Cardiometabolic risk assessment: an approach to the prevention of cardiovascular disease and diabetes mellitus. Clin Cornerstone 2005;7:716.

54. Alanazi KH, Abedi GR, Midgley CM, Alkhamis A, Alsaqer T, Almoaddi A et al. Diabetes Mellitus, Hypertension, and Death among 32 Patients with MERS-CoV Infection, Saudi Arabia. Emerg Infect Dis 2020;26:166-168.

55. Guan W, Liang W, Zhao Y, Liang H, Chen Z, Li Y, et al on behalf of China Medical Treatment Expert Group for Covid-19. Comorbidity and its impact on 1590 patients with Covid-19 in China: A Nationwide Analysis. Eur Resp. J, 2020;DOI: $10.1183 / 13993003.00547-20$

56. Stene LC, Rewers M. Immunology in the clinic review series; focus on type 1 diabetes and viruses: the enterovirus link to type 1 diabetes: critical review of human studies. Clin Exp Immunol 2012;168:12-23

57. Tiberti C, Buzzetti R, Anastasi E, Dotta F, Vasta M, Petrone A et al. Autoantibody negative new onset type 1 diabetic patients lacking high risk HLA alleles in a caucasian population: are these type $1 \mathrm{~b}$ diabetes cases? Diabetes Metab Res Rev 2000;16:8-14.

58. Yang JK, Lin SS, Ji XJ, Guo LM. Binding of SARS coronavirus to its receptor damages islets and causes acute diabetes. Acta Diabetol 2010;47:193-9

59. Gradman AH, Alfayoumi F. From left ventricular hypertrophy to congestive heart failure: management of hypertensive heart disease.Prog Cardiovasc Dis 2006;48:32641

60. Liu S, Horowitz JD. Interactions Between Influenza and Heart Failure Hospitalizations-Diagnostic and Pathogenetic Issues. JAMA Cardiol 2019;4:949-950

61. Mehra MR, Ruschitzka F. COVID-19 Illness and Heart Failure: A Missing Link? JACC: Heart Failure, 2020;Doi: 10.1016/j.jchf.2020.03.004

62. Rawal G, Kumar R, Yadav S, Amrita Singh. Anemia in Intensive Care: A Review of Current Concepts. J Crit Care Med 2016;2: 109-114

63. Reinelt P, Karth GD, Geppert A, Heinz G. Incidence and type of cardiac arrhythmias in critically ill patients: a single center experience in a medical-cardiological ICU. Intensive Care Med. 2001;27:1466-73).

64. Bonow RO, Fonarow GC, O'Gara PT, Yancy CW. Association of Coronavirus Disease 2019 (COVID-19) With Myocardial Injury and Mortality JAMA Cardiol. Published online March 27, 2020. doi:10.1001/jamacardio.2020.1105

65. Chen C, Zhou Y, Wang DW. SARS-CoV-2: a potential novel of fulminant myocarditis. Herz. 2020; https://doi.org/10.1007/s00059-020-04909-Z

66. Zeng JH, Liu Y, Yuan J, Wang F, Wu W, Li J et al. First Case of COVID-19 Infection with Fulminant Myocarditis Complication: Case Report and Insights. Preprints 2020;2020030180 doi: 10.20944/preprints202003.0180.v
67. Edwards S, Small JD, Geratz JD, Alexander LR, Baric RS. An Experimental Model for Myocarditis and Congestive Heart Failure after Rabbit Coronavirus Infection. J of Inf Dis 1992;165:134-40

68. Maier HK, Schips TG, Wietelmann A, Krüger M, Brunner C, Sauter M, et al Cardiomyocyte-specific I $\chi \mathrm{B}$ kinase $(\mathrm{IKK}) / \mathrm{NF}-\boldsymbol{} \mathrm{B}$ activation induces reversible inflammatory cardiomyopathy and heart failure. Proc Natl Acad Sci USA 2012;109:11794-11799

69. Schaufelberger M, Drexler H, Schieffer E, Swedberg K. Angiotensin-converting enzyme gene expression in skeletal muscle in patients with chronic heart failure. Card Fail 1998:4:185-191

70. Yang JK, Lin SS, Ji XJ, Guo LM. Binding of SARS coronavirus to its receptor damages islets and causes acute diabetes. Acta Diabetol 2010;47:193-199.

71. Tousoulis D, Antoniades C, Koumallos N, Stefanadis C. Pro-inflammatory cytokines in acute coronary syndromes: from bench to bedside. Cytokine Growth Factor Rev 2006; 17:225-233

72. Del Piero F. Equine Viral Arteritis. Vet et Pathol 2000;37:287-296. https://doi. org/10.1354/vp.37-4-287

73. Minahan RE, Bhardwaj A, Williams MA. Critical care monitoring for cerebrovascular disease. New Horiz 1997;5:406-21.1997

74. Landry GJ, Mostul CJ, Ahn DS, McLafferty BJ, Liem TK, Mitchell EL et al. Causes and outcomes of finger ischemia in hospitalized patients in the intensive care unit. J Vasc Surg 2018;68:1499-1504

75. Bloomgarden ZT. Diabetes and COVID-19. J Diabetes 2020;12:347-348 doi: 10.1111/1753-0407.13027.

76. Jager A, van Hinsbergh VWM, Kostense PJ, Emeis JJ, Yudkin JS, Nijpels G et al. The Hoorn Study. von Willebrand Factor, C-Reactive Protein, and 5-Year Mortality in Diabetic and Nondiabetic Subjects. Arteriosclerosis, Thrombosis, and Vascular Biology 1999;19:3071-3078.

77. Tikellis C, Pickering R, Tsorotes D, Du XJ, Kiriazis H, Nguyen-Huu TP et al. Interaction of diabetes and ACE2 in the pathogenesis of cardiovascular disease in experimental diabetes. Clin Sci (Lond) 2012;123:519-529.

78. Sano M. A new class of drugs for heart failure: SGLT2 inhibitors reduce sympathetic overactivity. J Cardiol 2018;71:471-476

79. Ho JE, Gona P, Pencina MJ, Tu JV, Austin PC, Vasan RS, et al. Discriminating clinical features of heart failure with preserved vs. reduced ejection fraction in the community. Eur Heart J 2012;33:1734-1741

80. American Diabetes Association: Older Adults: Standards of Medical Care in Diabetes 2020. Diabetes Care 2020; 43(Suppl 1): S152-S162

81. Le Couteur DG, Lakatta E. A vascular theory of aging. J Gerontol A Biol Sci Med Sci, 2010;65(10), 1025-1027. doi: 10.1093/gerona/glq135. Epub $2010 \mathrm{Jul} 22$

82. Altschul R. Endothelium: Its Development, Morphology, Function And Pathology, New York (\& London): The Macmillan Co, 1954;pp.xiv+157

83. Soria-Valles C, Santiago-Fernández O, Freije JM, López-Otín C. NF- $\chi B$ signaling as a driver of ageing. Int Rev Cell Mol Biol 2016;326:133-174

84. Sahoo S, Meijles DN, Pagano PJ. NADPH oxidases: key modulators in aging and age-related cardiovascular diseases?. Clin Sci (Lond) 2016;130:317-335. doi: 10.1042/ CS20150087.

85. Maamoun H, Abdelsalam SS, Zeidan A, Korashy HM, Agouni A. Endoplasmic Reticulum Stress: A Critical Molecular Driver of Endothelial Dysfunction and Cardiovascular Disturbances Associated with Diabetes Int J Mol Sci 2019;20: 1658. doi: 10.3390/ijms20071658

86. Back SH, Kang SW, Han J, Chung HT. Endoplasmic Reticulum Stress in the $\beta$-Cell Pathogenesis of Type 2 Diabetes. J of Diab Res, 2012;https://doi. org/10.1155/2012/618396

87. Chadwick SR, Lajoie P. Endoplasmic Reticulum Stress Coping Mechanisms and Lifespan Regulation in Health and Diseases. Cell Dev. Biol., 21 May 2019;https://doi. org/10.3389/fcell.2019.00084

88. Ding WX, Yin XM. Mitophagy: mechanisms, pathophysiological roles, and analysis. Biol Chem 2012;393:547-564

89. Aiello A, Farzaneh F, Candore G, Caruso C, Davinelli S, Gambino CM et al. Immunosenescence and Its Hallmarks: How to Oppose Aging Strategically? A Review of Potential Options for Therapeutic Intervention Front. Immunol 25 September 2019 https://doi.org/10.3389/fimmu.2019.02247

90. Tu W, Rao. Mechanisms Underlying T Cell Immunosenescence: Aging an Cytomegalovirus Infection Front. Microbiol. 27 December 2016; https://doi org/10.3389/fmicb.2016.02111

91. Bettigole SE, Glimcher LH. Endoplasmic Reticulum Stress in Immunity. Annu Rev Immunol 2015;33:107-138. DOI:10.1146/annurev-immunol-032414-112116 